\title{
Training safer surgeons: How do patients view the role of simulation in orthopaedic training?
}

\author{
${\text { Kashif } \text { Akhtar }^{1 \dagger} \text {, Kapil Sugand }}^{1 *}$, Asanka Wijendra ${ }^{1}$, Nigel J Standfield ${ }^{2}$, Justin P Cobb ${ }^{1}$ and Chinmay M Gupte
}

\begin{abstract}
Background: Simulation allows training without posing risk to patient safety. It has developed in response to the demand for patient safety and the reduced training times for surgeons. Whilst there is an increasing role of simulation in orthopaedic training, the perception of patients and the general public of this novel method is yet unknown. Patients and the public were given the opportunity to perform a diagnostic knee arthroscopy on a virtual reality ARTHRO Mentor simulator. After their practice session, participants answered a validated questionnaire based on a 5-point Likert Scale assessing their opinions on arthroscopic simulation. Primary objective was observing perception of patients on orthopaedic virtual reality simulation.

Findings: There were a total of 159 respondents, of which $86 \%$ were of the opinion that simulators are widely used in surgical training and $94 \%$ felt that they should be compulsory. $91 \%$ would feel safer having an operation by a surgeon trained on simulators, $87 \%$ desired their surgeon to be trained on simulators and $72 \%$ believed that additional simulator training resulted in better surgeons. Moreover, none of the respondents would want their operation to be performed by a surgeon who had not trained on a simulator. Cronbach's alpha was 0.969.

Conclusions: There is also a clear public consensus for this method of training to be more widely utilised and it would enhance public perception of safer training of orthopaedic surgeons. This study of public perception provides a mandate to increase investment and infrastructure in orthopaedic simulation as part of promoting clinical governance.
\end{abstract}

Keywords: Public perception, Surgical simulation, Perception, Arthroscopy, Virtual reality

\section{Background}

\section{Current challenges}

Enforced changes in postgraduate medical education are resulting in doctors attaining less experience than their predecessors. The European Working Time Directive (EWTD), changes to working practices and an increasing focus on patient safety have resulted in a significant reduction in the experience of surgical trainees [1]. This has implications for safety and training, particularly in craft surgical specialties where it has traditionally been a case of 'practice makes perfect'. Training has become more challenging as surgical procedures increase in complexity with newer minimally invasive and computer-assisted approaches that have their own inherent learning curves.

\footnotetext{
*Correspondence: ks704@ic.ac.uk

${ }^{\dagger}$ Equal contributors

'MSk Lab, Imperial College London, Charing Cross Hospital, London, W6 8RF, UK

Full list of author information is available at the end of the article
}

Trainers may also be reluctant to let trainees operate as independently as in previous generations in light of growing medico-legal claims, with more than $£ 800$ million of compensation paid out annually to patients by the NHS $[2,3]$.

\section{The role of simulation}

Medical educational and training has developed in an attempt to meet the current challenges. The role of simulation has increased significantly over the previous decade, with Simulated Patients (SP) and models [4] used in the re-enactment of a clinical setting within a controlled environment to learn and practise skills which can either be technical or non-technical (e.g. communication, leadership and teamwork). The aim is to demonstrate competence and confidence as well as reducing the risk of error when operating on patients.

Simulation offers a safe environment in which to augment psychomotor skills in a controlled and efficient 
manner without posing a risk to patients or to learners [5-7]. The Chief Medical Officer's Annual Report in 2008, Sir Liam Donaldson stated that "Simulation-based training should be fully integrated and funded within training programmes for clinicians at all stages" [3]. The General Medical Council (GMC) has also stressed the importance of simulation in training, whilst the Food and Drug Administration (FDA) stated, as far back as year 2004, that simulation should be an important part of any carotid artery stenting programme [8]. Trainees can hone their surgical skills safely, free of time and service pressures.

\section{Virtual reality simulators}

Much work has been done on the use of Virtual Reality (VR) simulators in laparoscopic surgery where skills learnt using the simulators have been shown to cross over into the clinical setting. This has been shown to shorten the learning curve on real laparoscopic procedures and to significantly reduce errors in live surgery [9-13]. This 'crossover' benefit of simulation has been proven repeatedly in laparoscopic surgery [14]. Simulation can provide objective data on economy of movement, time taken and collateral damage to anatomical structures. It can provide a means of repeated practice and facilitate self-directed learning at a pace appropriate for each individual. It has also recently been used in the selection of surgical trainees and career progression. The role of VR simulators in orthopaedic surgery is gradually increasing but it is still very much in its infancy with little evidence-based research available within current literature.

\section{Public involvement}

Healthcare is a public service paid for by citizens. Patient and public involvement is one of the pillars of clinical governance and there is a growing emphasis on patient choice over treatment and care, as well as involving patients in decisions about health care provision and the monitoring of outcomes. There has been a proliferation of questionnaires, interview schedules and rating scales to record measures of health and illness from the patient's point of view. Patient-Reported Outcome Measures (PROMs) assess the quality of care delivered to NHS patients from the patient perspective. PROMS have been collected by all providers of NHS-funded care since April 2009.

Patient education offers empowerment and ownership. The public is increasingly involved in developing and improving healthcare services and is represented by surveys on behalf of the Health Commission, Local Involvement Networks or Patient Forums, and as Lay Members on the Foundation Trust of Board of Governors.

With respect to surgery, public perception of surgical operations is often of structured and controlled events, where high levels of skill combined with clinical detachment are expected [15]. Furthermore, public opinion is resistant to patients being used as training material, especially if there is a compromise to patient safety. Simulation provides the opportunity to learn and rehearse operations in a safe, controlled and measurable environment [16] under appropriate supervision. Whilst there is public awareness of the role of simulators in the training of airline pilots, there is no published literature on the public and patient perception of simulation in surgical training.

\section{Methods}

At a public exhibition at the Science Museum of London, a high fidelity VR simulator (ARTHRO Mentor ${ }^{\mathrm{rns}}$, Simbionix, Ohio, USA) was made available for members of the public to use and perform diagnostic knee arthroscopy. A questionnaire was designed to gauge public opinion on the role of simulators in surgical training, based on a five-point Likert scale. 159 participants fully completed the questionnaire, which was initially validated by two independent consultant orthopaedic surgeons and two members of the public. Internal validity of the questionnaire was calculated using Cronbach's alpha. All data were analysed using Microsoft Excel (Microsoft, New

Table 1 Results of the public questionnaire (percentage - \%)

\begin{tabular}{|c|c|c|c|c|c|}
\hline Question & $\begin{array}{l}\text { Strongly } \\
\text { Disagree }\end{array}$ & Disagree & $\begin{array}{l}\text { Neither agree } \\
\text { or disagree }\end{array}$ & Agree & $\begin{array}{l}\text { Strongly } \\
\text { Agree }\end{array}$ \\
\hline 1. Simulators are widely used in surgical training & 0 & 6 & 8 & 48 & 38 \\
\hline 2. Simulators should be compulsory in surgical training & 0 & 1 & 5 & 38 & 59 \\
\hline 3. I would feel safer having an operation by a surgeon who has trained with simulators & 0 & 1 & 8 & 28 & 63 \\
\hline 4. I believe that surgeons trained additionally on simulators are better surgeons & 0 & 3 & 26 & 24 & 47 \\
\hline $\begin{array}{l}\text { 5. } 1 \text { wuold want my operation to be performed by a surgeon who has trained } \\
\text { additionally with simulators }\end{array}$ & 0 & 0 & 13 & 31 & 56 \\
\hline 6. I enjoyed using the simulators & 0 & 0 & 0 & 33 & 67 \\
\hline 7. I feel better informed about arthroscopic surgery having used a simulator & 0 & 0 & 9 & 41 & 50 \\
\hline
\end{tabular}




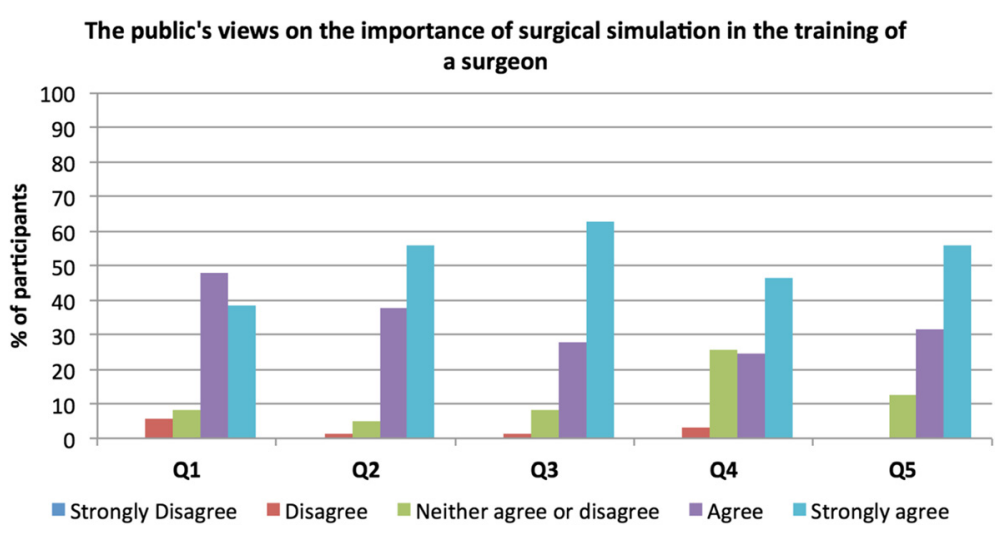

Figure 1 Public perception of simulation in surgical training.

York, USA). Ethics was granted by Imperial College Medical Education Ethics Committee (MEEC1213-17).

\section{Findings}

As seen in Table 1, all those taking part enjoyed using the simulator and $91 \%$ felt better informed about arthroscopy. $86 \%$ of people assumed that simulators are widely used in surgical training and 94\% felt that they should be compulsory. 91\% would feel safer having an operation by a surgeon trained on simulators, $87 \%$ desired their surgeon to be trained on simulators and $72 \%$ believed that additional simulator training resulted in better surgeons.

Moreover, none of the respondents would want their operation to be performed by a surgeon who had not trained on a simulator. The internal validity of the questionnaire using Cronbach's alpha was 0.969. Figure 1 displays visual comparisons between incidence of opinions for each question.

The role of simulation in educating surgeons is developing rapidly as a means of compensating for the significant changes to post-graduate training following the introduction of Modernising Medical Careers (MMC) and the EWTD. There is a need for doctors to gain experience in a safe, controlled environment away from service pressures. One way to address this is through simulation. Simulation provides a focused and effective way of repeatedly practising technical skills without risk to learner or patient. It permits standardised practice and can facilitate self-directed learning at a pace appropriate for each individual. VR simulation is playing an increasingly important role in surgical training as the quality and fidelity of simulators improve with time.

It is interesting that the vast majority of the public surveyed thought that simulators are widely used in surgical training when this is not the case, particularly in trauma and orthopaedic surgery. The overwhelming majority felt that simulators should be compulsory for trainee surgeons.
There was also a very high internal validity of the questionnaire among all participants. Simulation may save much money in the long-run since there is significant cost in training surgical trainees in the operating theatre. This has previously been estimated in USA as $\$ 53$ million a year [17].

Simulation may be heading towards becoming an integral part within both undergraduate and postgraduate training that can help to identify trainees with adequate psychomotor skills from an early stage to reduce risk of errors. Nevertheless, this concept has yet to be validated through further research and formally implemented. Albeit, there are some schools of surgery in the UK that have dedicated simulation centres and are supported by research grants, charities and deaneries. Within clinical practice, furthering education and patient empowerment are also major pillars of clinical governance and good medical practice.

\section{Conclusions}

Simulation may mitigate risks to patients, practitioners and organisations. It is clear that the public wishes for surgeons to minimise their learning curves away from patients, in a safe environment. People want their surgeons to be safe, accountable and accredited. VR simulation can facilitate this and there is a desire for this to be more widely integrated into surgical training curriculum.

\section{Abbreviations \\ EWTD: European Working Time Directive; FDA: Food and Drug Administration; GMC: General Medical Council; MMC: Modernising Medical Careers; NHS: National Health Service; PROMs: Patient Reported Outcome Measures; SP: Simulated Patient; USA: United States of America; VR: Virtual Reality.}

\section{Competing interests}

The authors declare that they have no competing interests.

\section{Authors' contributions}

KA \& KS produced the methodology and provided the participants with the simulator. KA, KS \& AW collected and analysed data. All authors contributed equally to writing and reviewing drafts of the manuscript. All authors read and approved the final manuscript. 


\section{Author details}

'MSk Lab, Imperial College London, Charing Cross Hospital, London, W6 8RF, UK. ${ }^{2}$ Postgraduate School of Surgery, London Deanery, Stewart House, 32

Russell Square, London, WC1B 5DN, UK.

Received: 28 November 2014 Accepted: 20 February 2015

Published online: 07 March 2015

\section{References}

1. Chikwe J, de Souza AC, Pepper JR. No time to train the surgeons. Brit Med J. 2004;328:418-9.

2. O. Bowcott: NHS compensation costs rise to $£ 807 \mathrm{~m}$. The Guardian newspaper, The Guardian News and Media Limited; London, United Kingdom 2009.

3. Health Do: Department of Health, 150 years of the annual report of the chief medical officer. On the state of public health 2008;55 2009.

4. Kneebone R, Nestel D, Wetzel C, Black S, Jacklin R, Aggarwal R, et al. The human face of simulation: patient-focused simulation training. Acad Med. 2006;81:919-24.

5. Kneebone R, Nestel D, Yadollahi F, Brown R, Nolan C, Durack J, et al. Assessing procedural skills in context: Exploring the feasibility of an Integrated Procedural Performance Instrument (IPPI). Med Educ. 2006;40:1105-14

6. Kneebone RL, Kidd J, Nestel D, Barnet A, Lo B, King R, et al. Blurring the boundaries: scenario-based simulation in a clinical setting. Med Educ. 2005;39:580-7.

7. Kneebone RL, Scott W, Darzi A, Horrocks M. Simulation and clinical practice: strengthening the relationship. Med Educ. 2004;38:1095-102.

8. Scott DJ, Cendan JC, Pugh CM, Minter RM, Dunnington GL, Kozar RA. The changing face of surgical education: simulation as the new paradigm. J Surg Res. 2008;147:189-93.

9. Aggarwal R, Tully A, Grantcharov T, Larsen CR, Miskry T, Farthing A, et al. Virtual reality simulation training can improve technical skills during laparoscopic salpingectomy for ectopic pregnancy. Brit J Obs Gyn. 2006;113:1382-7.

10. Aggarwal R, Ward J, Balasundaram I, Sains P, Athanasiou T, Darzi A. Proving the effectiveness of virtual reality simulation for training in laparoscopic surgery. Ann Surg. 2007;246:771-9.

11. Seymour NE, Gallagher AG, Roman SA, O'Brien MK, Bansal VK, Andersen DK, et al. Virtual reality training improves operating room performance: results of a randomized, double-blinded study. Ann Surg. 2002;236:458-63. discussion 63-4.

12. Ahlberg G, Enochsson L, Gallagher AG, Hedman L, Hogman C, McClusky 3rd $D A$, et al. Proficiency-based virtual reality training significantly reduces the error rate for residents during their first 10 laparoscopic cholecystectomies. Am J Surg. 2007;193:797-804.

13. Paisley AM, Baldwin P, Paterson-Brown S. Feasibility, reliability and validity of a new assessment form for use with basic surgical trainees. Am J Surg. 2001;182:24-9.

14. Darzi A, Smith S, Taffinder N. Assessing operative skill. Needs to become more objective. Brit Med J. 1999;318:887-8.

15. Kneebone R. The Art, science, and emulation of performance. In: International Symposium on Performance Science. Canada: University of Toronto; 2011.

16. Traynor O, Arnot RS, Robinson BA. The emerging role of simulation in surgical training. In: $76^{\text {th }}$ Annual Scientific Congress. New Zealand: The Royal Australasian College of Surgeons, Christchurch; 2007.

17. Bridges $M$, Diamond $\mathrm{DL}$. The financial impact of teaching surgical residents in the operating room. Am J Surg. 1999;177:28-32.

\section{Submit your next manuscript to BioMed Central and take full advantage of:}

- Convenient online submission

- Thorough peer review

- No space constraints or color figure charges

- Immediate publication on acceptance

- Inclusion in PubMed, CAS, Scopus and Google Scholar

- Research which is freely available for redistribution

Submit your manuscript at www.biomedcentral.com/submit 